\title{
A FORMAÇÃo do CARTÓGRAFO É O MUNDO: CORPORIFICAÇÃO E AFETABILIDADE ${ }^{\star}$
}

\author{
Laura Pozzana ${ }^{I \star \star}$ \\ ${ }^{I}$ Universidade Federal do Rio de Janeiro, Rio de Janeiro, RJ - Brasil
}

\section{Resumo}

Este texto discute a formação do cartógrafo colaborando na construção de pistas do método da cartografia. Ao considerar a processualidade na produção de conhecimento, o texto argumenta que tal formação se faz na abertura atenta do corpo ao plano coletivo de forças em meio ao mundo. $O$ aprendizado e a transformação do pesquisador se fazem no acompanhamento dos efeitos das ações de pesquisa, produzem habilidades e rigor ético. Varela e Latour nos dão suporte na afirmação de que a formação do cartógrafo se faz como inscrição corporal, é acompanhada por processos de corporificação do conhecimento $e$ práticas que configuram regimes de afetabilidade. Neste sentido, aponta para a necessidade de ativação do potencial de ser afetado para além de sua função sensivel trivial, ativando uma dimensão de virtualidade que só se amplia à medida que é exercitada. Concluímos que ao pensar na formação do cartógrafo pensamos na produção de mundo.

Palavras-chaves: método da cartografia; metodologia de pesquisa; formação; corpo; afeto.

\section{THE CARTOGRAPHER'S FORMATION IS THE WORLD:}

\author{
EMBODIMENT AND AFFECTABILITY
}

\begin{abstract}
This paper examines the cartographer's formation as a collaborator in the construction of clues in the method of cartography. By considering the process involved in the production of knowledge, the authors defend that this formation is achieved by the attentive opening of the body to the collective level of forces present in the world. The researcher's learning and transformation take place through the follow-up of the effects of research actions, developing abilities and ethical standards. Varela and Latour support our affirmation that the cartographer's formation occurs as a corporal inscription, alongside processes of embodiment

^O título é inspirado na exposição de Helio Oiticica "Museu é o Mundo", realizada no Rio de Janeiro em 2010. Agradeço a Beth Barros que foi parceira de escrita e pensamento deste texto até o momento quando coletivamente percebemos a riqueza do material e "separamos os bens" entre este texto e outro "A atividade do cartógrafo".

Apoio financeiro: $\mathrm{CNPq}$

$\star \star$ Psicóloga. Possui doutorado em Psicologia pela Universidade Federal do Rio de Janeiro, na linha de pesquisa Cognição e Subjetividade. Endereço: Universidade Federal do Rio de Janeiro - Instituto de Psicologia. Av. Pasteur, 250 - fundos. Praia Vermelha - Rio de Janeiro / RJ. CEP 22290-902.

E-mail: laura.pozzana@gmail.com
\end{abstract}


of knowledge and practices which constitute affectability structures. In this sense, it suggests the need to activate the potential to be affected beyond the trivial sensitive function, activating a virtual dimension that is only expanded to the extent that it is exercised. We conclude that, by reflecting on the cartographer's formation, we are reflecting on his construction of the world.

Keywords: cartography method; research methodology; formation; body; affect.

O meu destino eu não faço, o que vier eu traço (Paulo Leminski).

Gostaríamos de iniciar nossa aventura pelo tema da formação do cartógrafo com uma advertência: lendo o texto que se segue você não irá saber como se formar cartógrafo. Como foi indicado no livro Pistas do Método da Cartografia (PASSOS; KASTRUP; ESCÓSSIA, 2009), o aprendizado que nos forma, que nos traz ganhos, se faz sempre por inscrição corporal e não apenas por adesão teórica. Isso não significa que não haja um aporte teórico que acompanhe a produção de um corpo na formação do cartógrafo. Ele se faz principalmente com o trabalho de Francisco Varela (1996; VARELA, F.; THOMPSON; ROSCH, 2003) e a noção de coemergência entre conhecer, agir e criar. Mas não desanime, vamos trabalhar juntos. Acordado? Faça uma pequena pausa. Silencie e busque estar onde você está. Feche os olhos e volte a atenção para a sua respiração. Contemple seu estado atual, receba o mundo presente. Agora respire mais profundamente, inspire e, sobretudo, expire. Se sentir vontade, espreguice ganhando espaço e movendo articulações.

Propomos a leitura de um relato escrito na ocasião da exposição Museu é o Mundo, de Hélio Oiticica:

\section{Na Praça do Lido. Pode Brincar?}

20 de 10 de 2010. Toda semana passo um dia pela Praça do Lido, em Copacabana, por volta das $15 \mathrm{~h}$. Tenho um compromisso regular perto dali. $\mathrm{Na}$ semana passada, fui ao encontro da obra de Hélio Oiticica, pois havia sabido de um Bólide por lá. Entrei na Praça e busquei uma estrutura de museu, uma placa explicativa, algum mediador, alguém. Não havia nada. Nada não, de diferente vi uma piscina. Mas é isso? Uma espécie de Piscina Tone? Olhei em volta, contornei aquela "obra" e parecia que em nada ela intervinha no espaço e nas pessoas. Fui embora rápido, sem nem mesmo molhar a ponta dos dedos na água. Depois, meio arrependida pela passagem apressada, pensei: por que não fiquei um pouco mais? Ai, ai!

Hoje, por conta de algumas circunstâncias cheguei uma hora antes do meu compromisso. Resolvi aproveitar esse tempo na praça e explorar um pouco mais a presença do Bólide. Na chegada, a mesma impressão de antes. Estranhei a obra, uma espécie de piscina rasa, plástica, sem graça, solta, com uma aguinha parada e ninguém dando bola. Busquei um banco para sentar. Dos dois livres escolhi o 
que estava ao sol. Sentei, olhei o Bólide ali e nada. Quase sem pausa segui com perguntas: será que trocam a água? E à noite? Será que se pode brincar nessa piscina? Alguém toma conta? E a molecada de rua, faz bagunça? E a dengue, ninguém se preocupa? Deixei de ti-ti-ti e resolvi explorar alguns dos livros que eu havia comprado horas antes. O "universal" é uma invenção do pensamento grego, não apenas como conceito, mas como modo de ver a realidade, atitude diante dela. $\mathrm{O}$ sol estava forte e com o reflexo no branco da página estava difícil seguir lendo.

No banco à minha esquerda vejo se aproximar uma senhora. Com ela muitos pombos. Ela se senta e tira da bolsa um saco de farinha de milho. Questiono: Os pombos já a conhecem? Como eles se reúnem assim rapidamente? Eles sentem o milho mesmo no saco fechado dentro da bolsa? E ela continua a fazer o que parecia um ritual. Aos poucos vai alimentando os animais. Joga um pouco da farinha de um lado e um pouco do outro. Levanta e senta num ritmo próprio, parece curtir e me maravilho. Alguns pombos são mais atrevidos e vão comer na sua mão. Alguns se apoiam em seu ombro. Penso na generosidade dessa mulher em comprar milho para eles. A imagem me remete à Praça de São Marco em Veneza, sempre cheia de pombos. Lembro ainda de uma experiência de criança de alimentar pombos e de assustar-me na aproximação deles, nas patas frias e duras no meu braço. A senhora joga mais milho e a vejo balbuciar algo. Será que ela conversa com eles? Em que língua?

Volto à leitura. Afinal, "católico" é um termo grego que significa exatamente "universal". Giro a cabeça, olho para a senhora e ela está com um pombo preso nas mãos, apoiado no colo. Ela o capturou. Que susto! E o que estaria fazendo? Será que ela queria justamente pegar um para levar pra casa? Olho um pouco mais e vejo que ela está com uma tesourinha. Ai ai ai, será que vai cortar uma perninha para fazer macumba!? Vejo que ela corta um pouco de penas, algo leve. Apoia no banco o que corta e segue concentrada. Num momento ela me vê observando e tento mais uma vez voltar à leitura. Não consigo. Dou uma vagueada com a cabeça e observo outras pessoas na praça. Alguém deitado dormindo, um senhor sem camisa, outra senhora tomando café e duas amigas conversando. Volto a observá-la, não resisto. Queria não ver aquilo, pois me sinto tomada, impressionada. As perguntas se fazem em mim e começo a achar que ela estava arrancando as unhas daquele pombo. Que horror! Muitos pombos que ainda circulavam por ela são afastados quando a senhora joga no chão o saco da milharina, num gesto que comunica: acabou! Observo ao seu redor muitos pombos, cada um no seu lugar, descansando, pegando sol ou se coçando. Eles estão acompanhando a operação! A senhora ainda estava com sua bolsa pendurada nos ombros, como Joana Belarmino ao dar uma palestra no Instituto Benjamin Constant (IBC), instituto para cegos. Isto me faz lembrar de sua fala na ocasião: "vocês vêem de mais". Aquilo estava me tomando. A senhora está concentrada no que faz e nem se importa muito com o mundo à sua volta. Tira da bolsa algo. Logo penso, vai embalá-lo ou vai guardar estes restos para uma bruxaria. Observo um tubo, ela passa um creme no local onde corta. Ela é delicada, calma, mas a cena é 
forte. Busco desviar a atenção, mas sinto fazer parte daquele episódio, não posso sair e nem me preocupo com o passar do tempo. Quero disfarçar, mas não posso perder o momento seguinte. Como ficará o pombo?

De repente ela o solta. Ele manca. Vejo que uma das garras está disforme, inchada. Ele caminha saltitando e logo o perco de vista. A senhora se levanta e vem em minha direção. Ai, e agora? Não quero mirá-la, pois acho que ela é do mau, não quero que me passe nada. Que absurdo! Mas não posso evitar. A recebo meio de lado e ela diz: que coisa, como tem gente cruel nesse mundo! Tem homem aí que amarra as perninhas dos pombos. Às vezes os penduram nas árvores. Ela abre as mãos e me mostra a linha que havia retirado do pombo, um guardanapo com manchinhas de sangue e uns pedacinhos de carne. Como ela disse, precisou cortar um dedinho do pombo. Não sei no que acreditar. Tudo indica que a senhora foi ali para cuidar dos bichos. Ela segue falando: as pessoas acham que pombo é doença. Pense em quantas doenças tem por aí e não passam pelos pombos. Sou da área da saúde. Sou instrumentista. Sou católica-apostólica-romana. Trago minha tesourinha e Fibrase para que não saia muito sangue.

Nesse momento se aproximam do Bólide uma mulher e seu filho, uma criança de 6 ou 7 anos. Eles perguntam alto: pode brincar? Ninguém responde. A criança corre em direção aos pombos reunidos no chão e eles voam em ondas. Mais uma vez ele corre e os pombos se movem. Assim sorri e brinca. A senhora, séria ao meu lado, fala: não vai chutar não. Como tem gente mal educada nesse mundo!

Achando que o papo iria se alongar muito e que já estaria na minha hora, inclino o peito num movimento de levantar. A senhora diz: vou indo, quero comprar outros quilos de milho e voltar aqui para dar de comer a esses bichinhos. Ela vai e em voz alta preciso dizer: é, a senhora é boa!

Suspiro fundo. Vejo as horas. Haviam passado três minutos das $15 \mathrm{~h}$. Levanto e ao passar pelo Bólide molho os dedos da mão direita na água. Não faço o sinal da cruz, não sou católica. Passo uma mão na outra, abençoando a cena e lavando a alma.

Antes de entrar no local do meu compromisso, na Avenida Nossa Senhora de Copacabana, cruzo com ela jogando os restos de sua operação na lata do lixo. Ufa! Pode brincar!

Percepções e afetos em movimento. O Bólide, ${ }^{1}$ a moça que vai ao encontro da obra e a Praça do Lido despertam conexões, se fazem mutuamente e traçam caminhos. Estamos na esfera de um modo de pesquisar que não se separa de um plano de criação. Um cartógrafo nasce numa paisagem que habita com um corpo que se articula com os diferentes fragmentos da cena, prolonga-se como extensão de cada segmento dessa paisagem que se constitui com ele (SILVA, 2011). Processo de coengendramento. Wally Salomão (2003, p. 75) ressalta uma frase de Hélio Oiticica que nos serve para afirmar uma posição cartográfica que articula a experiência de criação com aquela da pesquisa: "habitar um recinto é mais do que estar nele, é crescer com ele, é dar significação à casca-ovo". 
O encontro com o Bólide opera deslocando a moça da esfera do reconhecimento e fazendo nascer percepções até então imperceptíveis. A obra ganha sentido quando o contingente e o inesperado mobilizam as relações fixas entre objetos, humanos e não humanos. Um corpo a convoca a estar com o Bólide, abre-se uma atenção ao presente que não se separa do passado e do futuro. Algo faz com que a moça permaneça na praça, mesmo desconfiando que a senhora é uma bruxa e está ali fazendo maldade. É convocada por presenças. O Bólide está e não está, precisa ser criado e explorado, descoberto. A obra aparece com a presença da moça, ao mesmo tempo em que a praça se faz nela, com a presença dela. A paisagem transforma-se, embora não seja possível dizer quando começou a transformação. Somos seres da/na impermanência.

\section{"UMA DIRETRIZ" NA FORMAÇÃO}

A abordagem clássica da ciência, pautada numa política cognitiva representacional, pressupõe sujeito e objeto como polos prévios ao processo do conhecer e busca leis e princípios invariantes; supõe que científico é aquilo que pode ser reproduzido com os mesmos resultados e garantido por um observador isento ao objeto de estudo. Nessa perspectiva, a experiência do pesquisador está excluída.

Para nós, interessa o acesso a um estofo diferente daquele proveniente de uma observação isolada daquilo que observa. Importa detectar a trama que acompanha o ato de conhecer e de criar um mundo, pois assim nos aproximamos do que engendra o pessoal e o coletivo; nos aproximamos do conhecimento concreto e articulado que tem efeitos políticos, éticos e estéticos.

Grande parte do modo como agimos e conhecemos se dá sem atenção e consciência ao que nos acontece. Não nos é dado saber como explorar o plano da experiência, isto não é imediato, requer aprendizagem. Por isso, acessálo e descrevê-lo é difícil. Com a elaboração de novas pistas para um método cartográfico, não podemos deixar de acentuar a necessidade de práticas que tornem possível uma atenção aberta aos processos em curso, que nos permitam saber com aquilo que nos faz viver. Mas como se efetiva a formação de um pesquisador a partir de uma postura conceitual-política que lida com o aspecto processual na produção de conhecimento e não com uma realidade dada?

Aqui, mais do que entender a formação em seu aspecto de produção de uma forma, baseada em modelos predeterminados, tomamos como ideia diretriz que o pesquisador cartógrafo é formado no acesso ao plano das forças, plano instituinte em movimento e transformação que não se separa do plano instituído. Se pudéssemos responder, de saída, como acessar tal plano, talvez este texto não tivesse serventia. Não há uma resposta geral. O processo de formação é sempre local e parcial, e por meio de práticas ganha corpo, mundo e língua (ROLNIK, 2007). Em vez da pergunta: como forma? Sustentamos esse não saber e brincamos: como força? Como estarmos atentos, abertos e sensíveis ao presente, forçados a pensar e a criar enquanto fazemos pesquisa? 
Explicitamos assim uma diretriz na pista para a formação do cartógrafo: o processo de formação se faz na abertura atenta do corpo ao plano coletivo de forças em meio ao mundo. $\mathrm{O}$ aprendizado e a transformação do pesquisador se fazem no acompanhamento dos efeitos das múltiplas práticas de pesquisa, práticas que dão acesso ao plano de onde emergem sujeito, objeto, campo, pesquisador, pesquisados, questões, textos, desvios e mundos. Essas práticas tomadas no tempo, por meio da repetição e da regularidade, produzem habilidades e rigor ético. Habilidade é tomada aqui como indica Varela (1996), como um know-how, um saber fazer, diferente de um know-what, um saber intencional ou um juízo racional. Dizemos que uma formação é acompanhada por processos de corporificação feitos por práticas compostas por afetos em trânsito. Eis um leme na formação.

\section{CORPORIFICAÇão}

Francisco Varela é um importante intercessor quando consideramos no processo de formação que conhecer, agir e criar se fazem juntos. Formar se aproxima mais de um movimento de fundação do que da apropriação de uma forma baseada em fundamentos e objetivos preestabelecidos. A tradição racionalista e cartesiana, que segundo Varela caracteriza o modo predominante como fomos educados no mundo ocidental, lida com o conhecimento de forma abstrata. Esta concepção é fruto de práticas que apartam o corpo das ações de reflexão e produzem saberes sobre as coisas e não com elas.

Varela (VARELA, F.; THOMPSON; ROSCH, 2003) observa que, no campo das ciências cognitivas, há em curso uma mudança paradigmática que se estende cada vez mais. Segundo palavras suas, "bem no centro desta visão emergente está a crença que as próprias unidades do conhecimento são fundamentalmente concretas, encarnadas, corporificadas, vividas" (VARELA, F.; THOMPSON; ROSCH, 2003, p. 72). A ação é guiada pelo corpo daquele que percebe, vive e experimenta em situação concreta. Valorizando a percepção local e concreta, Varela (VARELA, F.; THOMPSON; ROSCH, 2003, p. 79) indica que "a realidade não é projetada como algo dado: ela é dependente do sujeito da percepção, não porque ele a 'constrói' por um capricho, mas porque o que se considera como um mundo relevante é inseparável da estrutura do percipiente".

Varela (1996) considera que temos uma prontidão-para-ação própria para cada situação específica e que entre uma ação e outra experimentamos microperturbações continuamente. Tais prontidões-para-ação são microidentidades, e estas, em relação às situações encontradas, constituem micromundos, ambos entendidos como construções emergentes que brotam de uma fazer situado e nos constitui em relação direta com o concreto da experiência. Consideramos importante pontuar a inseparabilidade, nesse caso, dos termos micro e identidade. Microidentidades expressam disposições corporais, corposem-movimento-e-no-espaço, posturas e gestos articulados de modo situado, sempre vinculados a um micromundo, espaços-significados a partir de encontros histórico-culturais. Poderíamos dizer que as microidentidades se dão numa escala infra e supra-humana, não são características que definem um sujeito, estão em 
movimento com a vida, transitam. Podemos dizer que o susto de ver um pombo capturado por uma mulher, um peito apertado, uma respiração curta, uma bruxa, uma produção de questões, memórias, o fato de ter um compromisso regular e também de poder brincar, são algumas das múltiplas maneiras de nomear e relacionar complexos emergentes de microidentidades e micromundos.

Compartilhamos da ideia de Varela de que as microidentidades, como disposições à ação, são modos de agir e perceber em correspondência às situações, não são características fixas atreladas ao sujeito entendido de modo racional e central ao que lhe ocorre. Se tais ações são tomadas na riqueza do viver, não são dadas, não podem ser antecipadas, não devem ser abordadas a partir de regras gerais e abstratas. Varela (1996, p. 65) assim nos dá ferramentas para falarmos de um eu desprovido de eu, um eu não substancial que é melhor apreendido como interface, como "ponte entre o corpo corpóreo que é comum a todos os seres providos de sistema nervoso e a dinâmica social em que vivem os humanos".

Quando ressaltamos no início deste texto que tudo se passa quando não se encontra o que se espera, dizemos que conhecer não é reconhecer a realidade, não é representar, e que o concreto se atualiza nesses espaços de ruptura. $\mathrm{O}$ presente e o tempo importam na pesquisa que se faz como acompanhamento de processos. Pragmáticas performam mundos e vice- versa. Um aspecto importante na formação é desmontar o sistema de responsividade estímulo-resposta que considera o mundo dado e as ideias já formuladas. É preciso aproveitar os deslocamentos que viabilizam o acesso ao plano de transformação da vida, em vez de funcionar de modo mecânico, automático, no já dado sistema fechado sujeito-objeto. "Ao tentar conhecer o conhecer, acabamos por nos encontrar com nosso próprio ser” (SADE; KASTRUP, 2011, 144).

Uma ação em curso convoca diferentes competências, diferentes disposições corporais. Com práticas que oportunizam experimentações ganhamos habilidade ao transitarmos entre micromundos; ganhamos percepção e discernimento na lida com os diferentes encontros, com objetos humanos e não-humanos. Algo oposto à aplicação de regras. A inteligência emerge para guiar nossos atos em correspondência à textura das situações, e não independente delas. O sucesso de uma ação se dá pela capacidade de compor com a configuração de uma determinada paisagem. Trata-se, aqui, da emergência do senso comum, de um saber fazer, de um saber lidar com o momento específico no presente imediato.

Portanto, como guiar-se em situações locais? Como a percepção está ligada ao local e os locais mudam segundo a atividade do observador, aquilo que costuma ser previamente dado e independente daquele que percebe perde importância em comparação com a estrutura sensório-motora do agente cognitivo, que é a maneira pela qual o sistema nervoso liga superfícies sensoriais e motoras. Assim, é a corporificação daquele que percebe, a sua disposição e não um mundo abstrato, prévio, que guia uma determinada ação; é mais o corpo atento e aberto no espaço, do que conteúdos acumulados em aprendizados cristalizados. Varela dá um enfoque à percepção, sublinhando a inseparabilidade entre aquilo que conta 
como um mundo relevante para o observador e sua ação de perceber. Quanto ao entendimento do processo de percepção, Varela (2003, p. 80-81) se refere à concepção desenvolvida por Merleau-Ponty destacando que:

o organismo simultaneamente instrui e é modelado pelo ambiente. [...] Devemos ver o organismo e o ambiente como enlaçados em especificação e seleção recíprocas - uma questão da qual devemos nos recordar constantemente, pois ela é bastante contrária às visões herdadas, oriundas da tradição cartesiana.

Trazemos à baila um fragmento de uma Oficina de Movimento e Expressão Corporal que é realizada no Instituto Benjamin Constant. ${ }^{2}$ Esta experiência, parte de um relato de pesquisa, ajuda-nos a pensar a formação como um movimento de corporificação do conhecimento, onde as diferentes presenças em composição nos indicam por onde agir, conhecer e criar, nos indicam a emergência de micromundos e microidentidades dos trânsitos afetivos do presente. O "nós" é transitório assim como quando uma questão é formulada para fazer desvios e indicar caminhos. Observa-se, aqui, após anos de pesquisa, que "oficina", "participantes" e "a própria pesquisa" se fazem em colaboração recíproca - regime de afetabilidade.

Inspirada no Sistema Rio Aberto (cf. POZZANA, 2008) a oficina é movida para despertar presenças e abrir espaços para a expressividade dos afetos. O que está no horizonte é uma ampliação das conexões de cada um consigo mesmo e com o mundo (POZZANA, 2010, p. 76). Os participantes, aproximadamente 20, são pessoas cegas que perderam ou estão em processo de perda da visão.

A oficina foi sendo inventada pelos acontecimentos e produzindo uma aprendizagem coletiva. A questão central foi: como conduzir uma atividade utilizando o método da imitação em uma roda em que a maioria dos participantes não vê? Pudemos perceber como, com os encontros, modos de fazer foram inventados. Um modo de presentificar cada um na roda para os outros foi criado como um certo chamado, no qual cada um chamava a si em voz alta e era ecoado pelos outros. Percebemos como o fato de estar de mãos dadas, em roda, proporcionava paradoxalmente maior liberdade de movimentos para quem não pode ver. E recebemos ainda uma indicação da prática, a importância da palavra encarnada. Falar com presença e abertura produz conexão e faz mover.

Num dia de oficina (setembro de 2009), o início foi dedicado a fazer com que cada um observasse como estava física e emocionalmente. Nilton, um participante, falou alto: como está o astral? Depois foi feito um trabalho com o apoio dos pés no piso e um apoio do corpo nos pés. Seguimos, com atenção ao corpo, acompanhando o trajeto que ia do centro da terra ao alto. Ao chegar na cabeça, indiquei que sentissem um copo apoiado no alto, como uma coroa, que ajudasse a estarem verticais e com uma abertura da cabeça para o céu. Ocorreu, naquele momento, de indicar a percepção de uma energia que vem de cima. $\mathrm{Na}$ mesma hora, o Nilton falou: "agora vamos nos lembrar de quando víamos aquela luzinha lá no alto do céu, as estrelas". Sintonia. Sentimos juntos uma luz vindo 
de cima, entrando e atravessando nosso corpo. Um tempo depois, ao movermos a cabeça, Marlene disse em alta voz: "Assim nossas coroas vão cair". Nota-se que eles estavam ligados na proposta, a coroa nos unia abertos e atentos. Para terminar esse começo, avisei que deveríamos soltar nossas coroas no centro da roda. E aproveitarmos para soltar as ideias que temos de nós mesmos. Como pudemos aprender, a palavra é corpo e, na literalidade, conecta um grupo ao plano das forças.

Ao se deparar com algo inesperado, com o fato de não saber como conduzir pessoas que não podiam ver e, portanto, imitar, uma outra relação foise estabelecendo e guiando a todos. Esta outra relação que se foi estabelecendo e guiando a todos é a própria formação em operação, é um indício de que houve acesso ao plano coletivo de forças em meio ao mundo. Não pela apresentação de uma forma apreensível à distância, visualmente, e sim pela palavra-imagem que toca, reverbera em cada um, compõe (ativa) corpos de sensação. Não nos referimos a qualquer uso da palavra e sim daquele, em sintonia com o que acontece nos corpos e entre eles, no corpo em movimento pelo espaço, no espaço habitado por corpos - afetos em trânsito. A palavra encarnada, assim como uma mão, toca e é tocada quando partilhada. No relato anterior a imagem de uma coroa apoiada no alto da cabeça produziu uma postura, fez carne com a experiência, criando uma articulação entre os presentes. Um coletivo se fez (se reuniu). Mais do que visível, a coroa era celularmente tocada por cada um. Estar ali com uma coroa na cabeça era o conhecimento sendo corporificado numa postura, era experimentação, abertura para o céu, para o outro, para um grupo, para um plano comum.

Ao lembrarmos da corporificação do conhecimento e da indicação de Varela quando nos aponta que as estruturas cognitivas que nos permitem conhecer são concretas, encarnadas e vivas, precisamos pensar que essas estruturas têm uma história e são como aberturas para o tempo, para a virtualidade do viver. As estruturas são produzidas e produzem, são afetadas e também afetam. São mecanismos e comportam aberturas, repetições e diferenciações - afetos em trânsito. Se é com estruturas cognitivas que experienciamos algo, podemos dizer que afetos as acompanham e sintonias são feitas a despeito de nossa vontade ou planejamento. Há uma relação aqui com o que Varela (2003) chama de micromundo e microidentidade; há uma convocação para uma relação sensorial situada e ampliada. Nas brechas dos condicionamentos, do mecanicismo, passa uma vida, e devemos ser tocados por ela. Pontuamos que as estruturas são acompanhadas por experiências e vividas emocionalmente, a imagem é corpo, o medo é corpo e a coroa o é também. Ao darmos as mãos na roda um limite é explicitado e, paradoxalmente, muitos cegos enunciam ganhar liberdade para o movimento no espaço e consigo. É com o corpo que a liberdade é anunciada e não a despeito dele.

Notamos como não é por condução egoica, pela competência de um sujeito central na ação e na roda, que a oficina se dá. A virtualidade do $\mathrm{si}^{3}$ circula na roda. Por instantes nos reunimos com uma coroa aberta ao alto, lembramos das estrelas e a ideia que temos de nós mesmos pôde cair. 
Considerando que este relato é parte de uma pesquisa ${ }^{4}$ em curso que trabalha com o método da cartografia, pensamos que o tema da formação de um pesquisador neste sentido se explicita em estreita relação com a corporificação e a criação (que a rigor são sempre de um coletivo). Criação de modos de fazer, perceber, sentir, mover e conhecer, que não se separa do mundo, dos objetos humanos e não humanos em articulação - afetos em trânsito.

\section{Afetabilidade}

Podemos afirmar que o corpo se faz presente na prática de cartografia e é com ele que processos são acompanhados e sofrimentos (pathos) compartilhados. Mas como esse corpo aprende a ser sensível à investigação e ao objeto de estudo? Formar é um processo de aprendizagem também no plano dos afetos. Tratase de uma concepção de aprendizagem que não pode se reduzir a um debate psico-pedagógico ou técnico-metodológico. Pensar a formação, assim, implica a consideração constante de acompanhar os efeitos das práticas. $\mathrm{O}$ caminho de pesquisa se faz nos efeitos do campo em nós (pesquisadores-cartógrafos) e nos efeitos no campo da nossa presença-intervenção. Com Kastrup (2008) dizemos que tais efeitos podem ser rastreados no próprio curso da pesquisa, em seu problema, assim como no domínio de investigação e no texto da pesquisa.

Entendemos que a aprendizagem que faculta a formação do cartógrafo é produtora de subjetividade e objetividade, produz realidade. Um processo que não está entre um sujeito e um mundo a ser descoberto, mas produz sujeito e mundo. "A cartografia introduz o pesquisador numa rotina singular em que não se separa teoria e prática, espaços de reflexão e de ação. Conhecer, agir e habitar um território não são mais experiências distantes umas das outras" (ALVAREZ; PASSOS, 2009, p. 149). Sujeito e mundo são inventados no processo investigativo, marcados pelo inacabamento e pela experimentação.

Mas como esse corpo é criado? Aqui podemos pontuar a necessidade de dispositivos que produzam aberturas no já dado para fazer emergir o que se dá. Como coloca Francisco Varela (1996) a respeito das práticas que visam desenvolver a presença, podemos afirmar que o processo de formação do cartógrafo se aproxima da possibilidade de desidentificar-se dos hábitos que são executados sem uma atenção cuidadosa. Antes de aprender trata-se de um desprender-se. Como dissemos, é preciso desmanchar a responsividade que nos liga à vida de forma desconectada com a experiência. $\mathrm{O}$ aprendizado é literalmente corporificado e criado; requer tempo e espaço, respiração, articulação, atenção, disponibilidade para o desconhecido.

Bruno Latour (2007) nos ajuda a delinear essa formação como criação de um corpo de pesquisador-cartógrafo. Para Latour (2007) o corpo é definido pelos afetos, pelos encontros que se têm com entidades humanas e não humanas. $\mathrm{O}$ corpo é definido pelas paixões de que é capaz. O corpo não é ancoragem de algo superior - uma alma imortal, o universal, ou o pensamento - mas uma trajetória dinâmica na qual nós aprendemos a nos tornar sensíveis àquilo de que o mundo é feito. É preciso falar do corpo no mundo, sem desconectá-lo daquilo que o 
constitui. Para explicar um certo aprendizado no plano dos afetos, Latour (2007) dá como exemplo o treinamento de "narizes" para a indústria do perfume por meio do uso de maletas de odores como descrito por Geneviève Teil. Desde já, sublinhamos que esse nariz que se vai criar com o treino nos serve para pensar as múltiplas sensorialidades e ações que podem ser criadas no pesquisador em contato com o material e a prática de pesquisa cartográfica.

A maleta de odores é feita de uma série de fragrâncias puras aguçadamente distintas, arrumadas de maneira que se pode ir dos maiores aos menores contrastes de cheiro. $\mathrm{O}$ registro de tais contrastes é aprendido: começa-se com um nariz incapaz de dizer mais que "cheiroso e fedorento" e acaba-se relativamente rápido criando um "nariz" capaz de descriminar mais e mais sutis diferenças e sendo capaz de distingui-las umas das outras, mesmo quando elas estão disfarçadas ou misturadas. Por meio da prática de uma aprendizagem ganha-se um nariz que a permite habitar um mundo ricamente variado em termos de odor. Portanto, partes do corpo são progressivamente adquiridas ao mesmo tempo em que "contrapartes" do mundo estão sendo registradas de uma nova maneira. Adquirir um corpo é, assim, uma empreitada progressiva, que produz ao mesmo tempo um meio sensório e um mundo sensível, afetabilidade.

Este exemplo descrito por Latour (2007) é trazido aqui para sublinhar a necessidade de certos dispositivos de cultivo do pesquisador cartógrafo, posto que ele e seus objetos de pesquisa emergem das práticas. Dizemos de uma aprendizagem por cultivo ${ }^{5}$ e não por aquisição de informações. Assinalamos outra vez a coemergência entre pesquisador e pesquisa. A maleta com todos os elementos associados (professor, sessão) traz um corpo sensível e um mundo mais rico de odores. E, assim, podemos considerar múltiplos elementos na pesquisa produzindo afetabilidade nos encontros entre cartógrafos, relatos, entrevistas, artigos, teses e um mundo.

Latour (2007) fala de articulação para referir-se às diferenças. Um sujeito inarticulado é alguém que sempre sente, age e diz a mesma coisa. Um pesquisador inarticulado é aquele que vai a campo para confirmar o que já sabia, para coletar o que procurava, para aplicar uma teoria. Um sujeito articulado é alguém que aprende a ser afetado pelas outras pessoas e coisas. O pesquisador articulado vai a campo e move-se com ele para aprender, há um cultivo mútuo entre ele e aquilo que se faz presente no campo. Aqui o manejo da investigação se faz inseparável do manejo convocado em campo. Não há nada de interessante em um sujeito "sozinho", um sujeito é interessante quando ressoa com outros, é colocado em ação por novas entidades cujas diferenças foram corporificadas. Assim, a articulação não significa a habilidade de falar com autoridade, mas sim de falar em conexão com o plano dos afetos. Essa definição dinâmica nos faz pensar no aspecto relacional do corpo, pois ele se encontrará atravessado por múltiplos vetores, com um certo estado atencional, em uma pesquisa que se encontra viva o tempo todo. Isso quer dizer que o corpo ganha um limite concreto, encarnado, e, ao mesmo tempo, ganha liberdade, com a possibilidade de aprender, variar, transformar-se e devir outro. Este corpo é definido a partir do singular, daquilo 
que o move. Subjetividades e objetividades se fazem a partir dos diferentes ritmos, interesses, percepções e materialidades presentes. $\mathrm{O}$ cartógrafo se faz por um regime de afetabilidade, ele toca e é tocado.

Com a prática e com uma atenção que não visa atingir senão à própria experiência em curso, corpos mais dinâmicos e sensíveis são criados, abrindo a possibilidade de pesquisar na experimentação da variação e das diferenças. A prática de pesquisa é facilitada pela possibilidade de criar novas maneiras de ser e estar em campo. É por meio do praticar que a atividade de pesquisar cartograficamente ganha corpo e concomitantemente mundo. Formar e pesquisar se dão mutuamente.

Com Latour (2007), é interessante voltar à praça e perguntar ao corpo que se vai compondo com os múltiplos vetores como ele se dá (ou como ele se faz). Esse corpo tem uma história, que não é linear e não é fechada. Os pombos lembram Veneza e a infância, os meninos brincam, a moça pode ser uma bruxa e é enfermeira, inclinando o peito comunica-se partida. A moça se faz pombo com a mulher. E em que língua a mulher fala com os pombos? Há medo no ambiente existencial e acompanhando a cena experimentamos muito mais. Trata-se de uma história afetiva multivetorializada, que se fez na prática, vida aberta aos encontros. Esse corpo nasce com os acontecimentos, transformando-os em carne, encarnando experiências. A escuta, a fala, o contato, a postura, a capacidade de discernir o que paralisa e o que fomenta processos na pesquisa são múltiplas aprendizagens que envolvem uma rede de relações. Seria interessante perguntar ao Bólide como ele se faz (se dá). E aqui acentuamos que será nossa capacidade de articulação com o presente que vai captar esse processo. Coemergimos com os encontros suscitados, com modos de perceber, agir e criar.

A moça na praça é forçada a pensar por meio de seu inesperado encontro com o Bólide. Ali ela se articula, articulam-se afetos. Uma atração a levou ali, o Bólide não é o começo e sim o meio. Ambientação. Se tivesse encontrado apenas o esperado teria voltado pra casa inarticuladamente a mesma. Mas, ao se situar disponível para o que passava, habita um tempo diferente daquele cronológico, sem espaços abertos para devires. Ela transita com afetos, vai do desejo ao medo, do compromisso à possibilidade de brincar. Na praça, uma vida se faz rompendo a mecanicidade de corpos: uma moça, uma obra, uma piscina, um livro, um pombo, dois, três, um coletivo, uma operação, um saco de milho, quatro, cinco. Protocolos e pombos no colo: o Bólide faz conhecer. A bruxa é boa. Ufa! Pode brincar.

Seguimos nos interrogando e buscando formas de articular o fato de que as experiências e a invocação experimental envolvendo o corpo aparecem e sempre aparecerão de novos modos: tantos quantos seriam os indivíduos a experimentálas, como indica Hélio Oiticica (1986).

\section{FORMAÇÃo EXPERIMENTAÇÃo}

Antes de concluir, gostaríamos de ressaltar a importância de experimentações que possibilitam o acesso ao plano de transformação da vida, onde o sujeito da ação é o movimento (BERGSON, 1962). O cartógrafo é formado 
nas problematizações do mundo, nos desvios, nos lapsos, ali onde algo escapa ou onde não encontramos o que ansiamos encontrar. Por meio de práticas que nos fazem conhecer concretamente a condição acentrada e fragmentada do eu, a virtualidade do si tem lugar e nos faz duvidar do sujeito conhecedor como fonte do conhecimento. Nesse duvidar fazemos um movimento no mundo diferente do clássico-cartesiano. A dúvida, quando transformada em problema, quando articulada, é criação e produção de pensamento, é mergulho na experiência porque é com o corpo que uma questão se faz. É no corpo pensante e vibrante que uma perturbação engendra a vida que cria: corporificação e afetabilidade.

Experimentações que funcionam como dispositivos de formação são, por exemplo, os grupos de supervisão na clínica ou no campo de pesquisa propriamente dito. Os mais variados grupos de supervisão colocam em movimento e análise nossas resistências à mudança e nos fazem conhecer afetivamente outros modos de pensar e sentir, microidentidades e micromundos. Quando acontecimentos são narrados e compartilhados, personagens, lugares, conversas, texturas e imagens ganham espaço em nossas vidas. Somos forçados a pensar. Suspensões interrogam nossas posições de saber e poder. A coerência e o fechamento do ego falham, aparecem atos e o mundo se coloca. Por meio de fatos, do contar casos, da descrição de cenas, sonhos, pausas e acelerações, acompanhamos o que nos toca e como tudo se passa no campo, no setting, no texto, no laboratório, na oficina, em nós e no mundo. Como indica Varela (1996), a capacidade de expor nossas próprias tendências à fixação é uma atitude amigável conosco que faz expandir a atenção com a gente e o cuidado com os outros. Abrimo-nos para o coletivo.

Neste sentido, compartilhamos aqui uma curiosidade metodológica na escrita deste texto, apostando que o leitor possa captar nela mais um indício por onde se dão processos de formação. A escrita deste texto foi feita de maneira coletiva. Numa das primeiras rodadas, com o intuito de propor uma experimentação para a discussão do tema da formação, o texto "Na praça do Lido" entra na roda de discussão da construção das pistas do método da cartografia. O Bólide move e faz pensar.

Antes da leitura, uma pausa. Suspensão para uma abertura da atenção aos processos em curso - para o que se passa em cada um, abertura para um coletivo em trabalho, em criação, em corporificação. Sentados, nos apoiamos sobre nossos ísquios, respiramos em roda ao longo de nossas colunas. Apoiamos nossa mão direita nas costas do parceiro do lado direito. Respiramos juntos, apoiados na respiração, no outro, em nossos próprios eixos e em contato com a coluna ao nosso lado. Dali,foi feita em voz alta a leitura do relato na praça na ocasião da exposição Museu é o Mundo. O intuito era despertar a presença sensível-pensante, acessar experiências e compartilhar diferentes modos de ouvir, agir e reagir. Podemos dizer ainda que o interesse pelos efeitos da leitura era produzir pequenas descobertas em cada um, acessar modos de conhecer que fazem emergir e acompanham aquilo que conhecemos. Menos pelo seu conteúdo e mais pelos diferentes pensamentos e deslocamentos que aquela hora na praça apresentou, a experimentação convocava articulações. Pela força do texto nos reunimos na praça, o Bólide ganhou corpo e experiências apontaram para o tema da formação: "este texto precisa entrar no texto de formação!” A indicação foi praticamente unânime. 
Havia uma sintonia entre o que propôs Hélio Oiticica e aquilo que dizemos sobre a formação do cartógrafo. O Bólide estava lá e precisava ser descoberto. O Bólide está aqui e está corporificado. Desde o início o convite, ao despertar da presença, da sensorialidade, faz corpo com o que o artista indica com a convocação à busca do supra-sensorial em cada um: "dilatamento das capacidades sensoriais habituais, para a descoberta de seu centro criativo interior, de sua espontaneidade expressiva adormecida, condicionada ao cotidiano." (OITICICA, 2008, p. 193). O Bólide propõe interferências no campo da percepção e, desse modo, nos comportamentos, não para buscar um determinado condicionamento e sim para romper qualquer mecanicidade que aliena o ser humano de sua vida, de seu mundo e daquilo que produz através de automatismos, sem graus de liberdade em seus cotidianos. Segundo Angela Varela (2009) o supra-sensorial é um despertar, uma abertura para a totalidade dos sentidos. Pois, continua, "o estado criador de liberdade interior não advém de uma percepção de mundo onde predomina o exercício do intelecto" (VARELA, A., p. 89).

Por último, detectamos nas proposições de Hélio Oiticica um certo viés lúdico que atua na desmontagem de um racionalismo e de uma moralidade no cotidiano. O lúdico comparece na praça nas muitas interrogações e após elas, quando dizemos: Ufa! Pode brincar. E comparece na pesquisa quando ir a campo é dar as mãos e se sentir mais livre; é articular uma energia vinda do alto e a lembrança da estrela; é perceber na coroa a contração de um coletivo; é abaixar a cabeça e poder soltar as ideias que temos de nós mesmos. E afirmar nas imagens, nas palavras, conhecimento corporificado.

Cartografar é conectar afetos que nos surpreendem e, para tanto, na formação do cartógrafo é preciso ativar o potencial de ser afetado, educar o ouvido, os olhos, o nariz para que habitem durações não convencionais, para além de sua função sensível trivial, ativando algo de supra-sensível, dimensão de virtualidade que só se amplia à medida que é exercitada. $O$ cartógrafo, assim, vai criando corpo junto com a pesquisa. Trata-se de ganhar corpo para além de sua funcionalidade orgânica, biológica. Algo se passa, algo de virtual pode ser acessado, e aí está o corpo, o mundo e o tempo que passa.

Como a formação do cartógrafo cria mundos no mundo com o mundo? " $\mathrm{O}$ mundo não é algo que nos foi entregue: é algo que emerge de como nos movemos, tocamos, respiramos e comemos" (VARELA, F., 1996, p. 15). Damo-nos conta de que, ao pensarmos na formação do cartógrafo precisamos pensar na produção de mundo, assim como nos dispositivos de pesquisa - práticas complexas de onde emerge pesquisador e pesquisado, problema e campo, sujeito e objeto. Tratar desse tema é desdobrar a afirmação de que toda pesquisa é pesquisa intervenção (PASSOS; BENEVIDES DE BARROS, 2009) em outra articulação que não se separa desta engrenagem: toda pesquisa é pesquisa-formação! Pesquisaintervenção-formação é o mundo. "Ufa!" 


\section{Notas}

${ }^{1}$ Trata-se do Bólide “Área Água” exposto pela primeira vez nos jardins do Museu de Arte Moderna do Rio de Janeiro em 1970.

${ }^{2} \mathrm{O}$ Instituto Benjamin Constant (IBC) é um centro de referência nacional para questões da deficiência visual, localiza-se no bairro Urca da cidade Rio de Janeiro.

${ }^{3}$ A virtualidade do si é um modo, inspirado no trabalho de Varela (1996), de nos referirmos ao eu cognitivo não substancial, que não deixa de compor com um todo coerente na ação de modo situado.

${ }^{4}$ Esta pesquisa foi aprovada pelo Comitê de Ética Ana Nery da UFRJ.

${ }^{5}$ Para maior detalhamento da noção de cultivo conferir Depraz, Varela e Vermersch (2003).

\section{REFERÊNCIAS}

ALVAREZ, J.; PASSOS, E. Cartografar é habitar um território existencial em pistas do método da cartografia: pesquisa-intervenção e produção de subjetividade. In: PASSOS, E.; KASTRUP, V.; ESCÓSSIA, L. (Org.). Pistas do método da cartografia: pesquisa-intervenção e produção de subjetividade. Porto Alegre: Sulina, 2009. p. 131-149.

BERGSON, H. L'évolution crêatrice. Paris: Presses Universitaires de France, 1962.

DEPRAZ, N.; VARELA, F. VERMERSCH, P. On becoming aware: a pragmatic of experiencing. Philadelphia: Benjamin, 2003.

KASTRUP, V. O método da cartografia e os quatro níveis da pesquisa-intervenção. In: CASTRO, L. R. de; BESSET, V. L. (Org.). Pesquisa e intervenção na infância e adolescência. Rio de Janeiro: Trerepa/FAPERJ, 2008.

LATOUR, B. Como falar do corpo? A dimensão normativa dos estudos sobre a ciência. In: NUNES, J. A.; ROQUE, R. (Org.). Objetos impuros: experiências em estudos sociais da ciência. Porto: Afrontamento, 2007. p. 40-61.

OITICICA, H. Aspiro ao grande labirinto. Rio de Janeiro: Rocco, 1986.

OITICICA, H. Hélio Oiticica: a pintura depois do quadro. Rio de Janeiro: Silvia Roesler Edições de Arte, 2008.

PASSOS, E., BENEVIDES DE BARROS, R. A Cartografia como método de pesquisa-intervenção. In: PASSOS, E.; KASTRUP, V.; ESCÓSSIA, L. (Org.). Pistas do método da cartografia: pesquisa-intervenção e produção de subjetividade. Porto Alegre: Sulina, 2009. p. 17-31.

PASSOS, E.; KASTRUP, V.; ESCÓSSIA, L. (Org.). Pistas do método da cartografia: pesquisa-intervenção e produção de subjetividade. Porto Alegre, Sulina, 2009. 
POZZANA, L. O corpo em conexão: Sistema Rio Aberto. Niterói: Eduff, 2008.

POZZANA, L. Oficina de movimento e expressão com deficientes visuais: uma aprendizagem coletiva. In: MORAES, M.; KASTRUP. V. (Org.). Exercícios de ver e não ver: arte e pesquisa com pessoas com deficiência visual. Rio de Janeiro: Nau, 2010. p. 76-95.

ROLNIK, S. Cartografia sentimental: transformações contemporâneas do desejo. Porto Alegre: Sulina / UFRGS, 2007.

SADE, C.; KASTRUP, V. Atenção a si: da auto-observação à autoprodução. Estudos de Psicologia, v. 16, n. 2, p. 139-146, maio-ago. 2011.

SALOMÃO, W. Hélio Oiticica: qual é o parangolé? e outros escritos. Rio de Janeiro: Rocco, 2003.

SILVA, F. H. Atividade docente: implicações ético-formativas. 2011. Tese (Doutorado)-Programa de Pós-Graduação em Educação / Universidade Federal do Espírito Santo, Vitória, 2011.

VARELA, A. Um percurso nos Bólides de Hélio Oiticica. 2009. Dissertação (Mestrado)-Universidade de São Paulo, São Paulo, 2009.

VARELA, F. O Reencantamento do Concreto. Cadernos de Subjetividade, São Paulo, v. 1, n. 1, p. 71-86, set. 2003.

VARELA, F. Ética y accion. Santiago do Chile: Dólmen / Granica, 1996.

VARELA, F.; THOMPSON, E.; ROSCH, E. A mente incorporada: ciências cognitivas e experiência humana. Porto Alegre: Artmed, 2003.

Recebido em: 05 de maio de 2013

Aceito em: 10 de julho de 2013 